\title{
The neglected role of formal and informal institutions in women's entrepreneurship: a multi-level analysis
}

\section{Daniela Gimenez-Jimenez, et al. [full author details at the end of the article]}

Published online: 31 January 2020

(C) The Author(s) 2020

\begin{abstract}
This article draws upon institutional theory to investigate whether and to what extent informal institutions (masculinity, power distance, individualism, and indulgence) affect the relationship between formal institutions (the public expenditure on childcare and the length of parental leave) and the likelihood that women will become entrepreneurs. The main findings show that societies characterized by high masculinity and/or low individualism amplify the relationship between the public expenditure on childcare and the likelihood that women will become entrepreneurs. Instead, high-indulgent societies weaken the negative relationship between the length of parental leave and the likelihood that women will become entrepreneurs. We provide a nuanced picture of women's entrepreneurship by considering the neglected role of informal institutions.
\end{abstract}

\section{Resumen}

Partiendo de la teoría institucional, en este artículo se analiza en qué medida las instituciones informales (masculinidad, distancia al poder, individualismo e indulgencia) afectan la relación entre las instituciones formales (gasto público en el cuidado infantil y duración del permiso parental) y la probabilidad de que las mujeres se conviertan en empresarias. Los principales resultados del estudio muestran que en las sociedades caracterizadas por una alta masculinidad y/o bajo individualismo se refuerza la relación entre el gasto público en cuidado infantil y la probabilidad de que las mujeres sean empresarias. En cambio, en las sociedades altamente indulgentes se debilita la relación entre la duración del permiso parental y la probabilidad de ser empresaria. De esta manera, se vislumbra una imagen matizada del emprendimiento llevado a cabo por mujeres al considerar el papel descuidado de las instituciones informales.

Keywords Women's entrepreneurship · Female entrepreneurship · Formal institutions · Informal institutions $\cdot$ Institutional theory $\cdot$ Multi-level analysis

JEL classification $\mathrm{J} 16 \cdot \mathrm{J} 24 \cdot \mathrm{M} 13 \cdot \mathrm{L} 26$

\section{Summary highlights}

Contributions: This article contributes to the debate on the importance of including the institutional context when studying entrepreneurship. Additionally, we suggest that 
looking at the interactions between formal and informal institutions is key for understanding why women's participation in entrepreneurship varies across countries.

Research Question: How do informal institutions (culture) influence the relationship between formal institutions (family policies) and the likelihood that women will become entrepreneurs?

Methods and Information: By merging data from the 2010 Global Entrepreneurship Monitor, the Organization for Economic Co-operation and Development, the World Bank and Hofstede's culture dimensions, we generate a dataset of 20 countries and more than 27,200 women, including entrepreneurs and non-entrepreneurs. For testing our hypotheses, we use hierarchical linear modeling.

Results/Findings: Our results suggest that, in societies characterized by high masculinity and/or low individualism, the negative relationship is amplified between the public expenditure on childcare and the likelihood that women will become entrepreneurs. In contrast, in a society characterized by high indulgence, the negative relationship between the length of parental leave and the likelihood of becoming women entrepreneurs is weakened.

Theoretical Implications and Recommendations: This article contributes to the field of entrepreneurship because we observe that the interactions of formal and informal institutions affect women's likelihood of becoming entrepreneurs. By using a multilevel approach, we observe the role that culture, as an informal institution, plays in entrepreneurship, especially, women's entrepreneurship. Future research should increase the number of years used to examine the interaction between formal and informal institutions over time and study how these effects affect mum-entrepreneurs and women transition from the labor market to entrepreneurship.

Public Policy Recommendations: We suggest to policymakers, who wish to increase the number of women entrepreneurs, to consider informal institutions when creating public policies. Thus, policymakers should analyze the cultural context for designing specific and effective public policies.

\section{Introduction}

Research on women's entrepreneurship suggests that the number of women entrepreneurs globally varies widely (Kelley et al. 2017). In regions with similar institutional settings, women show comparable rates of participation in entrepreneurship (Klyver et al. 2013). The Economist (Burch 2013) noted that, in emerging markets, women entrepreneurs spend approximately $90 \%$ of their earnings on their families and in their communities, supporting the importance of women's entrepreneurship for economic growth. Despite several studies suggesting that informal institutions moderate the relationship between formal institutions (Helmke and Levitsky 2004; North 1990) and entrepreneurial behavior (Tonoyan et al. 2010; Welter and Smallbone 2011), it is still unclear whether and to what extent (positive or negative) informal institutions play 
a moderating role. In fact, as institutions are "the rule of the game" that constrain and determine human behavior (North 1990), they may generate positive or negative incentives for women to become entrepreneurs (Baughn et al. 2006; Elam and Terjesen 2010; Estrin and Mickiewicz 2011).

Institutional theorists argues that institutions are complex and can be formal or informal (North 1990). Formal institutions involve written rules, such as laws and regulations (North 1990; Williamson 2000), whereas informal institutions emerge from socially communicated information and are part of a heritage called "culture" (North 1990). In this article, we follow various authors who have applied the institutional approach to study entrepreneurship (e.g., Bruton et al. 2010; Welter and Smallbone 2011) and North (1990)'s discussion of public policies as formal institutions and some dimensions of culture as informal institutions. Previous studies of women's entrepreneurship have unbundled different institutional contexts to examine how institutions influence women and men entrepreneurs differently (Estrin and Mickiewicz 2011; Giménez and Calabrò 2018; Thébaud 2015) or how formal institutions influence women entrepreneurs (Goltz et al. 2015; Lee et al. 2011). However, little is known about how informal institutions moderate the relationship between formal institutions and the likelihood that women will become entrepreneurs.

This article draws upon institutional theory (North 1990) to address this gap by examining how informal institutions (masculinity, power distance, individualism, and indulgence) influence the relationship between formal institutions (the public expenditure on childcare and the length of parental leave) and the likelihood that women will become entrepreneurs. To accomplish this goal, we use a multi-level modeling approach and data from the 2010 Global Entrepreneurship Monitor (GEM), the Organization for Economic Co-operation and Development (OECD), the World Bank and Hofstede's culture dimensions to generate a dataset of 20 countries and more than 27,200 women, including entrepreneurs and non-entrepreneurs. By combining these different sources into a unique dataset, we can pay close attention to the roles of social structures surrounding women entrepreneurship (Ahl and Nelson 2010). The findings suggest that, in societies characterized by high masculinity or low individualism, the negative relationship is amplified between the public expenditure on childcare and the likelihood that women will become entrepreneurs. However, in a society characterized by high indulgence, the negative relationship between the length of parental leave and the likelihood of becoming women entrepreneurs is weakened.

Our study contributes to the literature in two ways. We contribute to the debate on the importance of including the institutional context when studying entrepreneurship (De Clercq et al. 2013; Schölin et al. 2017; Stephan et al. 2015) by using a multilevel approach and offering a comprehensive view of the effects of formal and informal institutions on the entrepreneurial behaviors of women in various countries. Moreover, we move beyond the exploration of direct effects (e.g., Baughn et al. 2006; Estrin and Mickiewicz 2011; Kobeissi 2010; Yousafzai et al. 2015) and suggest that looking at the interactions between formal and informal institutions is of key importance to grasp women's entrepreneurship and understand how women's participation in entrepreneurship varies across countries. Specifically, we suggest that, among the different types of informal institutions, culture plays a crucial role in understanding entrepreneurship (Bruton et al. 2008; Engelen et al. 2009; Oo et al. 2018). Finally, we contribute to the legitimization of institutional theory (Brush et al. 
2009; Giménez and Calabrò 2018) as a theoretical lens that may shed new light on the structural incentives that influence women entrepreneurs and illuminate the "hidden" institutional constraints that women perceive or face when performing entrepreneurial activities.

\section{Theoretical framework: institutions and women entrepreneurs}

Institutions are "the rules of the game" of a society that function as constraints and define human interactions (North 1990). Institutions are classified into formal institutions - such as constitutions, laws and property rights - and informal institutions derived from culture (North 1990). Formal and informal institutions are intertwined, and interactions between them establish an equilibrium in the economy (Aoki 2001). Thus, the rules of the game define the institutional evolution of an economy and the way entrepreneurs are constrained, enabled and guided by the institutional framework in which they are embedded (Nooteboom 2002). Although North (1990) considers entrepreneurs in general (e.g., social entrepreneurs, economic entrepreneurs, etc.), in this article, we refer to entrepreneurs as individuals who have established businesses. According to Williamson (2000), institutional theory proposes the concept of the "embeddedness" of informal institutions in society, in which culture plays a large role. The nature of informal institutions is abstract, and they mostly go unnoticed (Helmke and Levitsky 2004). However, they interact with formal institutions and affect individual behaviors (North 1990). We therefore suggest that institutional theory may shed light on the "hidden" institutions that may amplify or mitigate the effect of informal institutions on women entrepreneurs (Brush et al. 2009).

Individual characteristics and attributes may influence the likelihood that women will become entrepreneurs (e.g., Langowitz and Minniti 2007; McGowan et al. 2012) and that institutions play a crucial role (e.g., Baughn et al. 2006). Several authors have suggested that women's entrepreneurship has a multi-level nature (Elam and Terjesen 2010; Terjesen et al. 2013). Brush et al. (2009) propose a holistic framework that is gender aware and goes a step beyond the market by including motherhood and meso- and macro-environmental factors. In this context, it is important to understand the way in which institutions (e.g., public policies and culture) influence women's entrepreneurship because these institutions cannot be easily changed and are difficult to control (Brush et al. 2009). In recent years, an effort has been made to understand the influence of formal institutions on the likelihood that women will become entrepreneurs (Thébaud 2016). For example, Goltz et al. (2015) observe that interactions of different public policies (e.g., gender quotas within parliaments, the rule of law, etc.) positively affect women's likelihood of becoming entrepreneurs. However, recent studies have also attempted to understand the effects of informal institutions on women's entrepreneurship (e.g., Baughn et al. 2006). Baughn et al. (2006) show that culture affects the proportion of women and men entrepreneurs differently; in particular, societies that have strong entrepreneurial cultures have higher proportions of women entrepreneurs. In sum, the results of these studies suggest that formal and informal institutions help explain the observed gender differences in the likelihood of becoming entrepreneurs across countries (Elam and Terjesen 2010; Estrin and Mickiewicz 2011) and the gender gap in entrepreneurial activity globally (Thébaud 2015). 


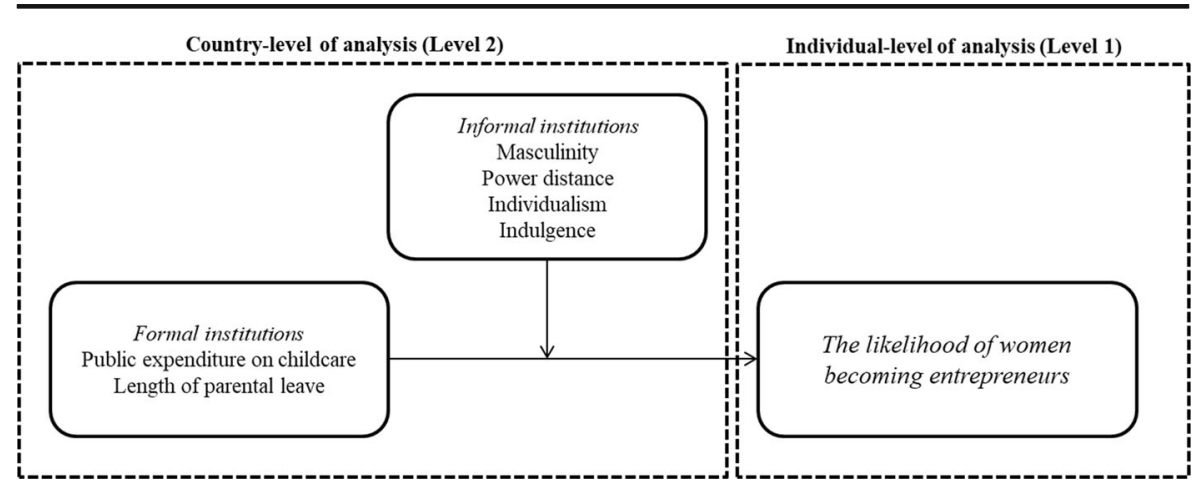

Fig. 1 Research model

According to some scholars, the interaction between formal and informal institutions (Helmke and Levitsky 2004; North 1990) affects entrepreneurial behavior (Giménez and Calabrò 2018; Tonoyan et al. 2010). We examine how the interaction between informal and formal institutions influences the likelihood that women will become entrepreneurs. Our research model is shown in Fig. 1.

\section{Family policies as formal institutions}

Public expenditure on childcare Family policies are provided and implemented by states as part of the public service sector to facilitate childcare and to support parents (especially women) in achieving a proper balance between family and professional responsibilities (Gornick and Meyers 2003; Mandel and Semyonov 2006). Family policies such as public childcare are common in welfare states and contribute to increasing female labor market participation (Mandel and Semyonov 2006). Given the nature of this family policy, evidence suggests that the public expenditure on childcare is positively associated with female labor market participation (Gornick and Meyers 2009). The literature on women's entrepreneurship has observed a negative effect of the public expenditure on childcare on the likelihood that women will become entrepreneurs (Elam and Terjesen 2010; Estrin and Mickiewicz 2011). This phenomenon is evident in countries with no state childcare provisions or laws (e.g., Canada), where the likelihood of women's entrepreneurship is higher, in contrast to countries with high childcare provisions (e.g., Denmark), where the likelihood of women's entrepreneurship is lower (Thébaud 2015). These findings may be explained by the fact that having states spend on childcare fosters gender equality in the labor market (Pettit and Hook 2009). Thus, childcare helps women continue to work and reduces their childcare costs (Thébaud 2015). On the contrary, in countries with no or low state childcare provision, entrepreneurship is perceived as a way to balance work and family life (Buttner and Moore 1997; McGowan et al. 2012). We expect that, in developed economies, such as Scandinavian countries that provide large sums of public childcare funding (Fuwa and Cohen 2007), women may exhibit a lower likelihood of starting businesses than in countries such as Australia and the USA with low public expenditures on childcare (Hegewisch and Gornick 2011).

The length of parental leave Parental leave reflects the benefits that the state offers to working parents (Mandel and Semyonov 2006). Thus, it is related the division of 
housework and varies in length, coverage of wages, and restrictions on who (men and/ or women) is eligible to take the leave (Fuwa and Cohen 2007). The length of parental leave is considered to be positively related to the female labor force participation (e.g., Bergemann and Riphahn 2010) and reduces the gender earning disparity (Mandel and Semyonov 2005). Nevertheless, studies on the relationship between the length of parental leave and women's entrepreneurship have shown mixed results. For example, Estrin and Mickiewicz (2011) observe that longer parental leaves significantly reduce the likelihood that women will become entrepreneurs. In contrast, Thébaud (2015) does not find a significant relationship between parental leave and the likelihood of women becoming entrepreneurs.

The length of parental leave affects new mothers because, in countries with little or no parental leave (e.g., the USA), women need to reduce their working hours, take very short leaves or exit the labor market (Hegewisch and Gornick 2011) to take care of their children. This situation may partially explain why women perceive that opening their own businesses allows them to better balance work and family life (McGowan et al. 2012). New mothers in countries with medium levels of parental leave (e.g., up to 6 months) are able to care for their children with appropriate timing (e.g., Bertrand et al. 2010). Women and men thus spend similar amounts of time at work and are more competitive (Bertrand et al. 2010). However, parental leave that is too long may affect the accumulation of professional experience, leading women to become less competitive in the labor market (e.g., Misra et al. 2007). We thus formulate the following hypothesis:

Hypothesis 1: There is a negative relationship between family policies (the public expenditure on childcare and the length of parental leave) and the likelihood that women will become entrepreneurs.

\section{The moderating role of informal institutions}

North (1990, p. 73) argues that the interaction of formal and informal institutions (among other factors, such as technology and income) determines "the potential wealthmaximization opportunities of entrepreneurs." Based on this idea, scholars have found that the interaction between formal and informal institutions has an effect on individual behaviors, particularly on entrepreneurial behaviors. However, this effect has not been properly investigated in women's entrepreneurship research. Research on women's entrepreneurship has focused on examining the differential effects of institutions on men and women entrepreneurs (Estrin and Mickiewicz 2011; Thébaud 2015) as well as understanding how formal institutions influence women entrepreneurs (e.g., Goltz et al. 2015). These studies show the complex interaction between formal and informal institutions and how they determine women and men's economic behaviors (North 1990). Little is known about how the interaction between formal and informal institutions affects women entrepreneurs. Therefore, in this article, instead of distinguishing between the influence of formal and informal institutions, we examine the interactions between them by examining how informal institutions (masculinity, power distance, individualism, and indulgence) moderate the effects of formal institutions on the likelihood that women will become entrepreneurs. We argue that masculinity, power distance, individualism, and 
indulgence moderate this relationship because informal institutions may influence women entrepreneurs more than formal institutions do (Alvarez and Urbano 2011; Noguera et al. 2013). Therefore, informal institutions, particularly those related to gender norms, are strong determinants of women's engagement in economic activities, especially becoming entrepreneurs (Klyver et al. 2013).

We use Hofstede's conceptualization of culture ${ }^{1}$ (masculinity, power distance, individualism and indulgence), which has been used extensively in the entrepreneurship literature to understand the role of culture in entrepreneurship (e.g., Mitchell et al. 2000). Hofstede (2001) defines culture as the "collective programming of the mind that distinguishes the members of one group or category of people from another." Therefore, Hofstede's culture dimensions capture the informal institutions suggested by North. North (1990) suggests that culture is a common set of values, which gives a language-based conceptual framework for encoding and interpreting information on this set of values and knowledge. Culture is taken for granted and is not subjected to scrutiny or judgment (Jepperson 1991). Therefore, culture becomes part of the mindset and affects individual behaviors. Hofstede's definition of culture is closely connected to informal institutions. We believe that culture could show us a comprehensive overview of how the values of different societies provide an answer to why women participation in entrepreneurship is generally low and varies greatly worldwide. Indeed, investigating cultural dimensions as informal institutions could reveal some gendered components at the society level and the way that societies perceive entrepreneurship (Bruton et al. 2010).

Power distance Power distance refers to the way that power is distributed in society. This informal institution is related to the extent to which individuals perceive power and its distribution (Hofstede 2001). Societies with large power distance are characterized by strongly unequal hierarchies and income distributions (Hofstede 2011) and maintain strong traditional gender roles in society (Parboteeah et al. 2008). Mitchell et al. (2000) observe that power distance influences the skills, attributes, and opportunity recognition of individuals and their decision to become entrepreneurs. All societies are unequal, but some are more unequal than others (Hofstede 2011). Thus, in small power distance societies, roles are established by convenience, and income distribution is rather equal (Hofstede 2011). In this situation, women may perceive a more egalitarian society in which they have similar opportunities as men. Therefore, power distance may not have a significant effect on women entrepreneurs. By contrast, in large power distance societies, entrepreneurs believe that social distinction is based on merit (McGrath et al. 1992). Thus, women may perceive higher inequalities (Hofstede 1980) and may prefer to create new businesses to reduce gender and income inequalities in such societies (Bird and Brush 2002).

In contrast, in large power distance societies, since the state does not fund daycare (Hegewisch and Gornick 2011), women may not have the same amount of time as men to accumulate professional experience as they need to take care of their children. Moreover, this lack of support from the state increases childcare costs, which may lead women to become entrepreneurs to reduce those costs.

\footnotetext{
${ }^{1}$ Hofstede (1980) proposes other culture dimensions that can be used to describe a given society. Individualism refers to individual accomplishment and the differentiation of the individual. Uncertainty avoidance describes the extent to which individuals in a society feel threatened by unclear or unknown situations.
} 
Lengthy parental leaves help to balance inequalities in the labor market, which are also related to high power distance. In this case, women may perceive that they have sufficient support from formal institutions. Hence, women may prefer to enter the labor market rather than to start a business. Therefore, we hypothesize the following:

Hypothesis 2a: The negative relationship between the public expenditure on childcare and the likelihood that women will become entrepreneurs is moderated by the level of power distance in a country such that the relationship is weaker in large power distance countries.

Hypothesis $2 \mathrm{~b}$ : The negative relationship between the length of parental leave and the likelihood that women will become entrepreneurs is moderated by the level of power distance in a country such that the relationship is weaker in large power distance countries.

Masculinity Masculinity indicates that societies maintain clear distinctions in gender roles, so that, for example, in some societies men are supposed to be assertive, independent breadwinners, and women are supposed to be modest, tender, and concerned about their families (Hofstede 2001). These differences between sexes involve not only emotion but also the social role of gender in society (Hofstede 2001) and affect the division of labor (Fuwa 2004). McGrath et al. (1992) observe that being an entrepreneur is closely associated with "earnings, recognition, advancement and challenge," which are traits of masculine societies (Hofstede 1980). These characteristics of entrepreneurs are associated with the way in which men are expected to act but conflict with the notion of how women should act (Henry and Marlow 2014). Evidence suggests that in highly masculine countries such as Japan and Italy, men have few household responsibilities, whereas in low-masculinity societies (e.g., Sweden and Norway), women and men share housework equally (Geist 2005). This finding may partially explain why women perceive entrepreneurship as a way of balancing work and family life in highly masculine countries (McGowan et al. 2012) because women's roles in this type of society are defined by their family responsibilities and duties (Baughn et al. 2006). However, in less-masculine societies, women are empowered, and they usually have more opportunities to participate in economic and political life (Fletcher 2006). When the state invests less in public childcare, women may perceive that the creation of a new business provides a way to balance work and family life (Buttner and Moore 1997; McGowan et al. 2012). In contrast, in highly masculine societies and societies with high public childcare expenditures, women may perceive that the labor market offers greater security.

Entrepreneurship may become a good solution for balancing work and family life. In highly masculine societies with short or no parental leave, new mothers are the primary caregivers, and taking care of their children is considered their duty (Baughn et al. 2006). Hence, short or no parental leave leads new mothers to reduce their working hours or to exit the labor market (Hegewisch and Gornick 2011). Long parental leave may negatively influence a woman's likelihood of becoming an entrepreneur in a highly masculine society. Because women are expected to take care of the family and the household (Thébaud 2015), they prefer to be part of the labor market by drawing upon the greater support for and time to take care of their 
children and household responsibilities. These arguments are summarized in the following hypotheses:

Hypothesis 3a: The negative relationship between the public expenditure on childcare and the likelihood that women will become entrepreneurs is moderated by the level of masculinity in a country such that the relationship is weaker in highly masculine countries.

Hypothesis $3 \mathrm{~b}$ : The negative relationship between the length of parental leave and the likelihood that women will become entrepreneurs is moderated by the level of masculinity in a country such that the relationship is weaker in highly masculine countries.

Individualism According to Hofstede (1980), individualism is the degree of emphasis on individual accomplishment interest and the differentiation of the individual from the others. Hofstede (1983) suggests that, "everybody is supposed to look after the interest of his or her in-group. In exchange, the in-group will protect them when they are in trouble. We see that both the individualist and the collectivist societies are integrated wholes, but while the individualistic society is loosely integrated, the collectivist one is tightly integrated" (Hofstede 1983). In low-individualistic societies (e.g., Chile, Greece, and Mexico) personal relationships take priority over tasks and businesses, while in individualistic societies (e.g., USA, Australia, and Great Britain), the task and the businesses are more important than the personal relationships (Hofstede 2001). McGrath et al. (1992) observe that entrepreneurial attributes are closely related to Hofstede's results of his individualism dimension. Their results suggest that, for entrepreneurs, "success is: owning your own company," which is highly related to Hofstede's result of individual initiative and great sense of achievement. These findings are in line with the characteristic of individualistic societies in which individual self-interest prevails over the interest of the group (Hofstede 2001). In high-individualistic societies, gender traditional roles are less embedded, leading to more opportunities to participate in both the labor market (Fletcher 2006) and in entrepreneurship. For this reason, an increase of the public expenditure on childcare would not affect women's likelihood of becoming entrepreneurs because these women are empowered. However, in low-individualistic societies, the benefit from the states and family cohesiveness (Hofstede 2001) generates persistent gender traditional roles. Because of these gender roles, women are also expected to care for their extended family, including parents, grandparents, and uncles (Hofstede 2001); thus, supporting the family is always prioritized. This situation might increase the interest of women towards entrepreneurship and thus the likelihood of becoming entrepreneurs.

We do not expect that the length of parental leave will significantly influence the likelihood that women will become entrepreneurs in high-individualistic societies. This situation occurs as women focus on their tasks and businesses, which is not related to the length of parental leave. On the contrary, in low-individualistic societies, women may receive support from their families businesses (Powell and Eddleston 2013), but their families expect similar support from them. Hence, we formulate the following hypothesis:

Hypothesis 4a: The negative relationship between the public expenditure on childcare and the likelihood that women will become entrepreneurs is moderated 
by the level of individualism in a country such that the relationship is weaker in low-individualistic countries.

Hypothesis $4 \mathrm{~b}$ : The negative relationship between the length of parental leave and the likelihood that women will become entrepreneurs is moderated by the level of individualism in a country such that the relationship is weaker in lowindividualistic countries.

Indulgence Indulgence refers to a tendency to enable the relatively free gratification of basic and natural desires related to enjoying life and having fun. Its opposite is restraint, which positions "a society that controls gratification and regulates it by means of strict social norms" (Hofstede 2011). Some characteristics of indulgent societies are that people declare they are very happy, they value freedom of speech, they perceive that they have personal control, they pay a high importance to leisure, they are better educated, and birthrates are higher (Hofstede 2011). Countries such as Australia, Denmark and Mexico show high indulgence, in contrast to Hungary, Japan, and Korea, where low indulgence prevails. However, Mediterranean countries such as Spain, Portugal, and Greece are positioned in the middle. We consider that indulgence has an impact on the effect of the public expenditure on childcare and the length of parental leave such that the negative relationship between family policies and the likelihood of women becoming entrepreneurs is weakened at increased levels of indulgence. In high-indulgent societies, people perceive that they have life control; therefore, a country with a high expenditure on childcare would positively influence women who wish to become entrepreneurs. New mothers perceive that public childcare is a benefit to them, giving them work-family balance (Mattis 2004). However, when indulgence decreases, individuals act within the social convention of society (Hofstede et al. 2010). Women in these societies may perceive that becoming entrepreneurs is not well accepted (Baughn et al. 2006b) because entrepreneurship is overall considered an unconventional way of obtaining income. Consequently, the negative effect of the public expenditure on childcare is amplified by low-indulgent societies.

A similar situation may occur in the way indulgence influences the relationship between the length of parental leave and the likelihood of women becoming entrepreneurs. As indulgence increases, individuals perceive personal life control and leisure to be highly important (Hofstede 2011). Thus, new mothers would perceive creating their businesses is a way of fulling their desire to work while having more time to raise their children (Buttner and Moore 1997). When indulgence decreases, the negative effect of the length of parental leave on women's likelihood to become entrepreneurs is amplified. The underlying logic is that the job market could be more attractive than becoming an entrepreneur, as women perceive support from the states, but this situation occurs only when they are part of the labor market. Thus, we hypothesize as follows:

Hypothesis 5a: The negative relationship between the public expenditure on childcare and the likelihood that women will become entrepreneurs is moderated by the level of indulgence in a country such that the relationship is weaker in highindulgent countries. 
Hypothesis 5b: The negative relationship between the length of parental leave and the likelihood that women will become entrepreneurs is moderated by the level of indulgence in a country such that the relationship is stronger in highindulgent countries.

\section{Methods}

\section{Data collection and sample}

Individual and macro-level data were gathered from multiple sources. Individual-level data, such as our dependent variable, were collected through the Adult Population Survey (APS) conducted by the GEM. The GEM APS collected data from approximately 2000 adults (aged 18 to 64) in each country. The data were collected through telephone or face-to-face interviews. This survey has been used in various comparative studies (De Clercq et al. 2013), supporting the notion that it provides reliable and valid data (Reynolds et al. 2005; Thébaud 2015), especially for the use of multi-level modeling techniques. The process of merging the data was as follows. We used the data from the GEM, which collects data in 60 countries. The GEM teams collected data from individuals in different countries; in each country, the data collected varies from 500 to 13,000 individuals. In 2010, the GEM project collected from 176,684 participants, of which 85,560 were male and 91,124 were female. Since our aim is to understand the effect of family policies as formal institutions and cultural dimensions as informal institutions, we needed to merge the data with the OECD data, the Hofstede data and the World Bank Group. We used the OECD data for obtaining family policy information. Due to the limited number of countries that participate in the OECD, the data reduce from 60 countries to 21 countries. Then, we included Hofstede's data, which were collected from 101 countries and included more than 50 questions for capturing the cultural dimensions (Hofstede et al. 2010). We merged the data with Hofstede cultural dimensions, representing those countries that needed to match the countries from the OECD data. While merging the datasets, we observed that only one country did not have information on Hofstede cultural dimensions; thus, we had a sample of 20 countries. We also used data from the World Bank Group for controlling at the country level, again necessitating a match with the countries in the sample. In sum, we excluded observations with missing data and observations from countries where information on public policies and cultural dimensions are not available from the OECD family dataset, the World Bank or Hofstede's culture dimensions. Therefore, our final sample is 27,200 women from 20 countries (Australia, Belgium, Denmark, Finland, France, Germany, Greece, Hungary, Ireland, Italy, Japan, Korea, Mexico, the Netherlands, Norway, Portugal, Spain, Sweden, the UK, and the USA).

\section{Measures}

Dependent variable The GEM dataset distinguishes three types of entrepreneurs (Reynolds et al. 2005). First are individuals who are actively involved in the process 
of starting a new venture but have not launched it. These are named nascent entrepreneurs. Second is new entrepreneurs, representing those who have been operating their businesses for more than 3 months but less than 42 months and have paid some wages. Finally, established entrepreneurs refers to individuals who have owned and managed a business for 42 months or longer. Following Autio et al. (2013), we focused on the first two types of entrepreneurs - individuals who are in the process of starting businesses and those who have had businesses no longer than 42 months because the aspects of the theory focus on becoming entrepreneurs. The dependent variable was a dummy (yes), representing that a woman qualified as a nascent or new entrepreneur in the GEM data.

Independent variables From the OECD family dataset, we obtain public expenditure on childcare and the length of parental leave for each country. These are well-known and frequently used variables for testing the effects of formal institutions (Elam and Terjesen 2010; Estrin and Mickiewicz 2011). Public expenditure on childcare indicates the financial support provided for families with children receiving formal daycare services (OECD 2015). Length of parental leave is the length of employment-protected leave available to mothers and fathers around the time of childbirth (OECD 2015).

Moderating variables We use Hofstede's culture dimensions from the original dataset for the variables masculinity vs. femininity, power distance, individualism vs. collectivism, and indulgence vs. restraint, which are operationalized as continuous measures. Masculinity vs. femininity ranges from 0 to 100 , where " 0 " indicates the leastmasculine society and " 100 " the most masculine. Similar to the previous dimension, power distance ranges from 0 to 100 , where " 0 " is the lowest power distance society. Individualism vs. collectivism also ranges from 0 to 100 , with " 0 " being the lowest individualistic society (collectivistic society). Finally, indulgence vs. restraint ranges from 0 to 100 , where " 0 " is the lowest indulgence society (restraint society). We did not include uncertainty avoidance and the long-term dimension due to the high collinearity with our independent variables (above 0.60 ) as shown in Table 2. Hofstede's culture dimensions are well recognized and used in many studies of entrepreneurship ( $\mathrm{Li}$ and Zahra 2012). Although Hofstede's culture dimensions have been strongly criticized (e.g., Baskerville 2003), they are also widely used and accepted measures of culture (e.g., Simón-Moya et al. 2014) due to their predictive power, reliability (Trompenaars and Hampden-Turner 1998), and relative invariability over the long term (Li and Zahra 2012) (for further information, see the Table 1).

Control variables At the individual level, we follow previous literature (e.g., Autio et al. 2013) and control for age from 18 to 64 years old. Furthermore, because entrepreneurial activity is best represented by an inverted $U$ shape (Levesque and Minniti 2006), we control for age squared. We also control for self-efficacy ("1") because evidence suggests that the relationship between self-efficacy and the likelihood that a woman will become an entrepreneur is positive and significant (e.g., Langowitz and Minniti 2007). Several studies have observed that the perception of good opportunities, role models, and the individual level of education are positively associated with the likelihood of becoming an entrepreneur (Langowitz and Minniti 2007). We therefore control for opportunities (dummy variable coded as "1"), knowing other entrepreneurs (dummy variable coded as "1") and level of education (categorical 


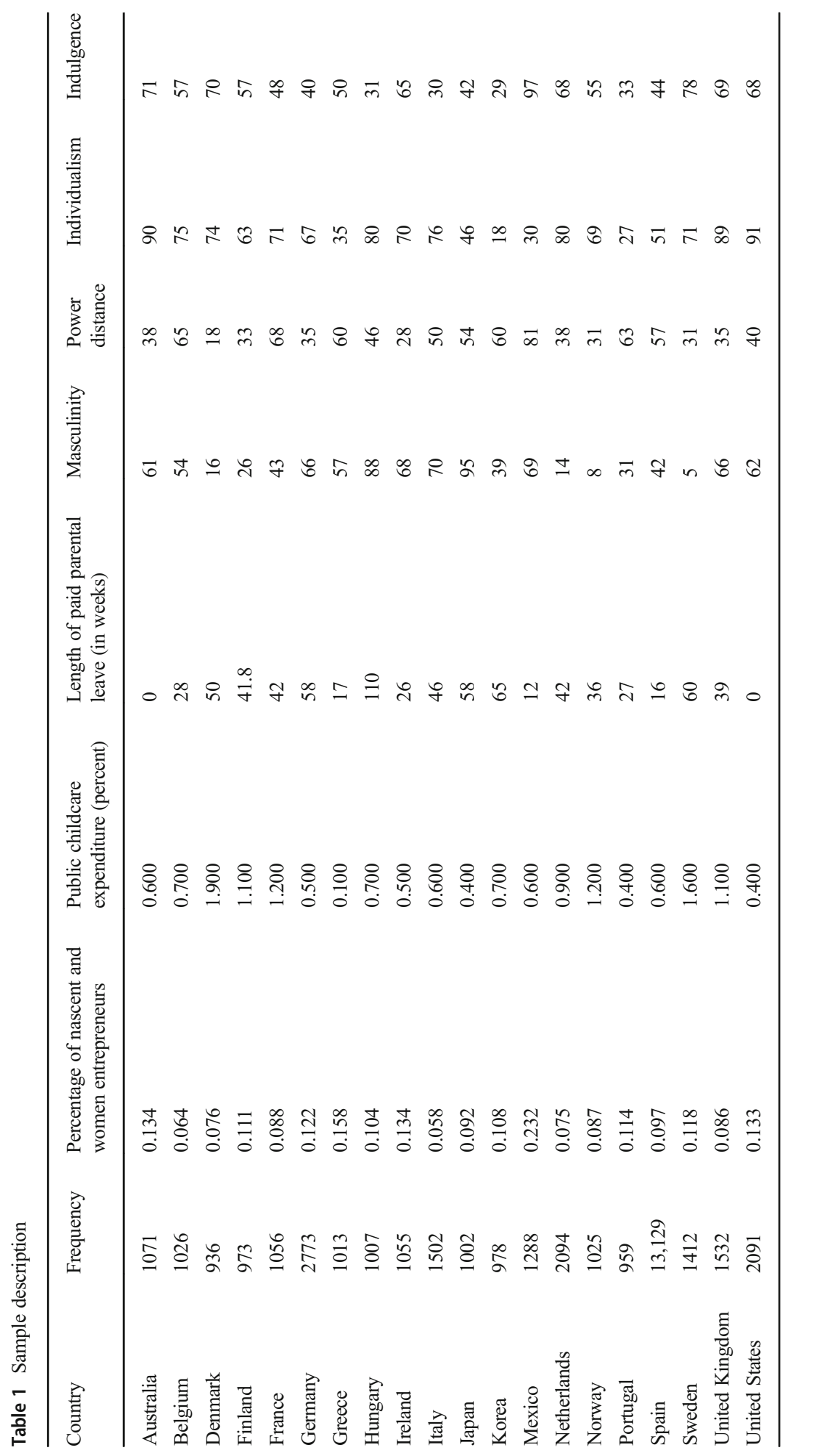


variable coded as " 0 " for no education, " 1 " for some secondary education, " 2 " for a secondary degree, " 3 " for post-secondary education, and " 4 " for graduate education).

We also control for country-level variables. We control for domestic product growth during the year 2010. Following previous literature in women's entrepreneurship (Elam and Terjesen 2010; Verheul et al. 2006), we control for the percent of female unemployment $^{2}$ (a continuous variable that ranges from 0 to $100 \%$ ).

\section{Analysis}

Our dependent variable is a dummy variable (the likelihood that women will become entrepreneurs). Thus, we use a hierarchical linear modeling (HLM) approach: logistic regression with random effects. This technique allows us to analyze the relationship between the predictor variable and a binary outcome in the case of non-independent outcomes (Hox et al. 2010). This technique assumes that unobserved country-specific characteristics $(\mathrm{u} 0 \mathrm{j})$, which are randomly distributed with mean zero, constant variance and uncorrelated predictors, covary. Thus, this technique allows us to observe that the constant term varies randomly among countries (Autio et al. 2013). HLM has several advantages over conventional regressions because discounting the interdependency between the individual and the country level can lead to inaccurate estimates (Hofmann 1997). The observations within groups (e.g., countries) are correlated and not independently distributed (Aguinis et al. 2013; Hox et al. 2010). Thus, multi-level analysis is an appropriate technique for analyzing our theoretical model. To facilitate the interpretation, all predictor variables are z-standardized (Autio et al. 2013; Stephan et al. 2015).

As previously mentioned, in the first step of the hierarchical analysis, we include only the dependent and control variables (individual and country level) (model 1). In the second step, we add the control and independent variables (country level) (model 2). Finally, we add the (country level) predictor and moderator variables in models 3,4 , 5, 6, and 7. All models are estimated using STATA 13.0.

\section{Results}

Tables 1 and 2 present the descriptive statistics and the correlation matrix of all the variables, respectively. As the results showed, uncertainty avoidance and the long-term dimensions were highly correlated with our independent variables. For this reason, we did not include these cultural dimensions in our analyses. The variables were tested for possible collinearity by estimating the variance inflation factor (VIF) (all < 1.700), which met the recommended standards (Hair et al. 1998). The VIF test thus suggests that multicollinearity does not affect the results (Table 3 ).

Table 4 reports the results of the HLM analyses. In model 1, we included the control variables at both the individual and country levels to obtain the variance of the likelihood of becoming a woman entrepreneur. All control variables at the individual

\footnotetext{
${ }^{2}$ The International Labor Organization (ILO) assesses the number of jobless people as those who would like to work and are actively seeking a job.
} 


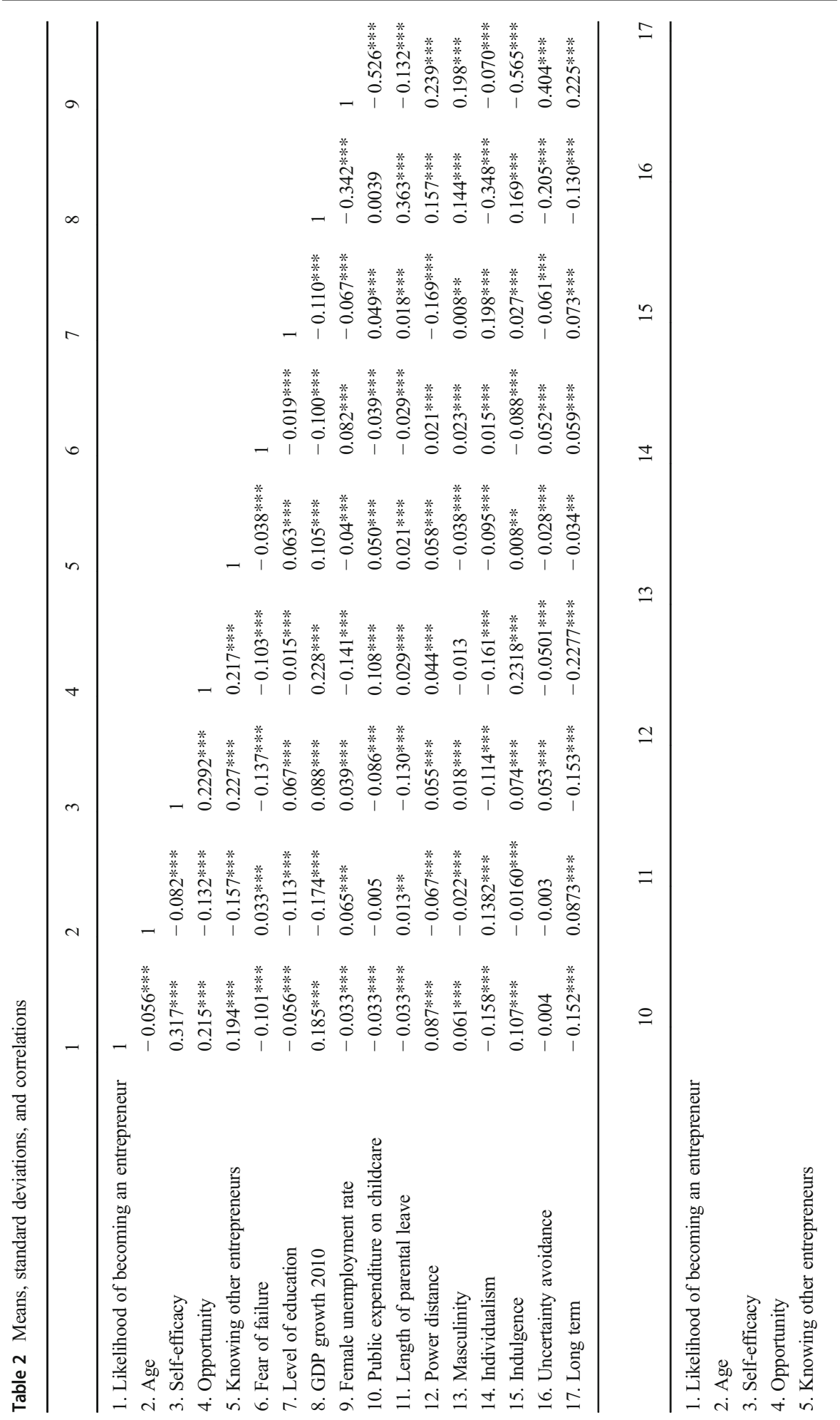




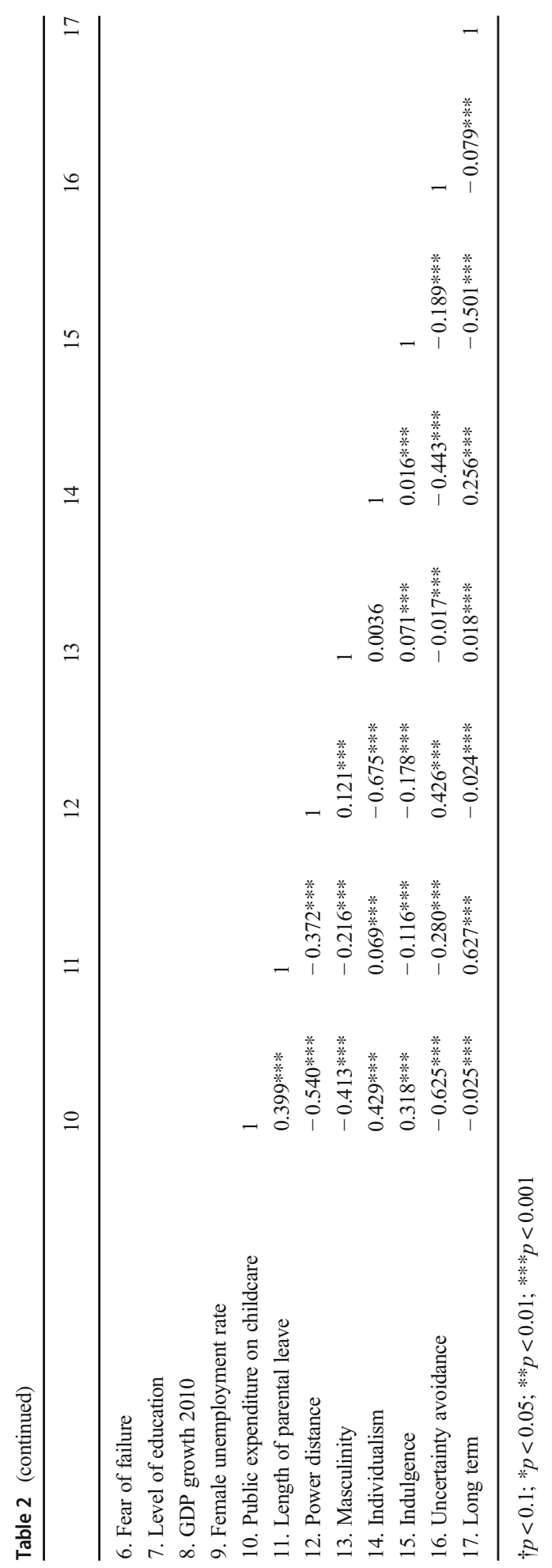




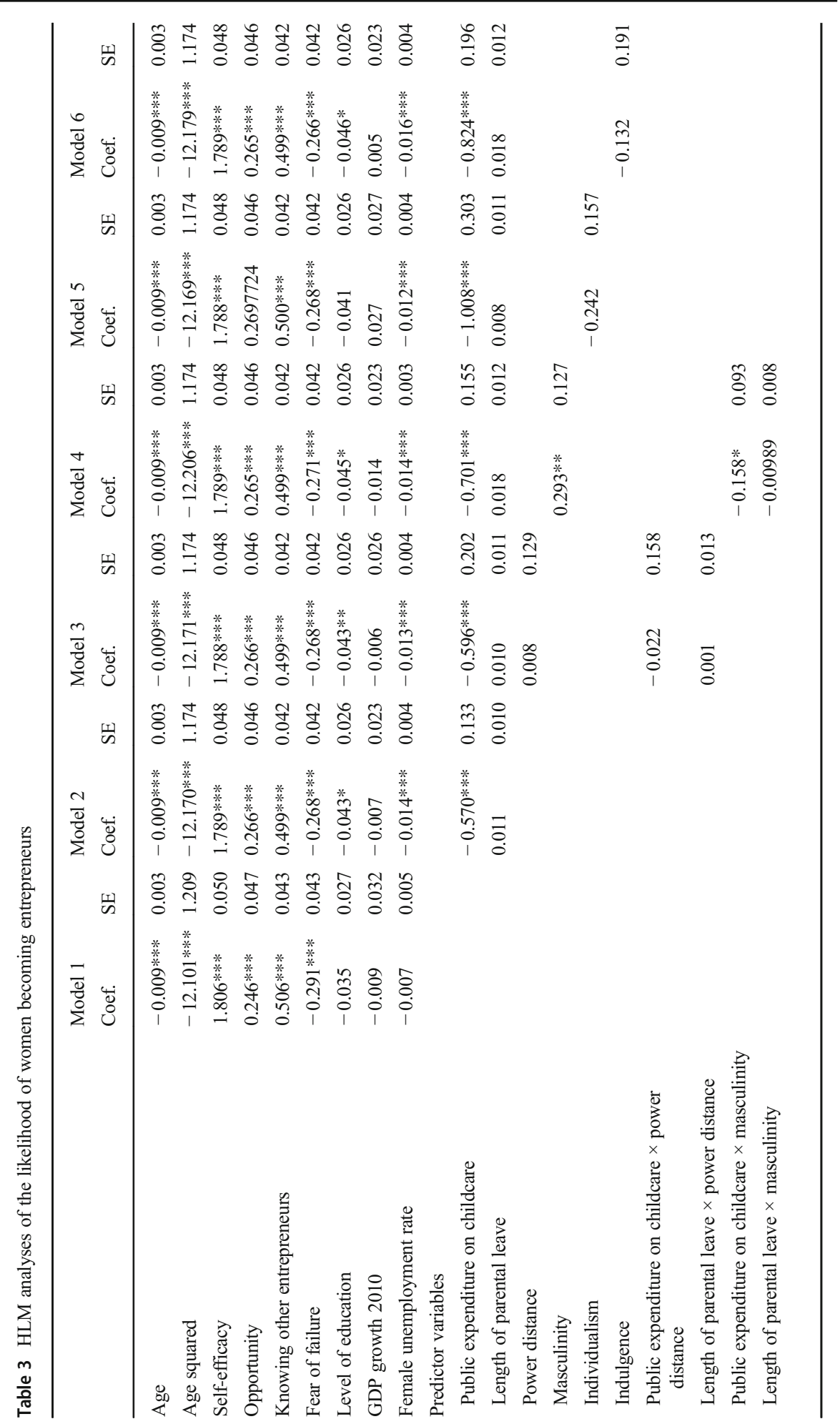




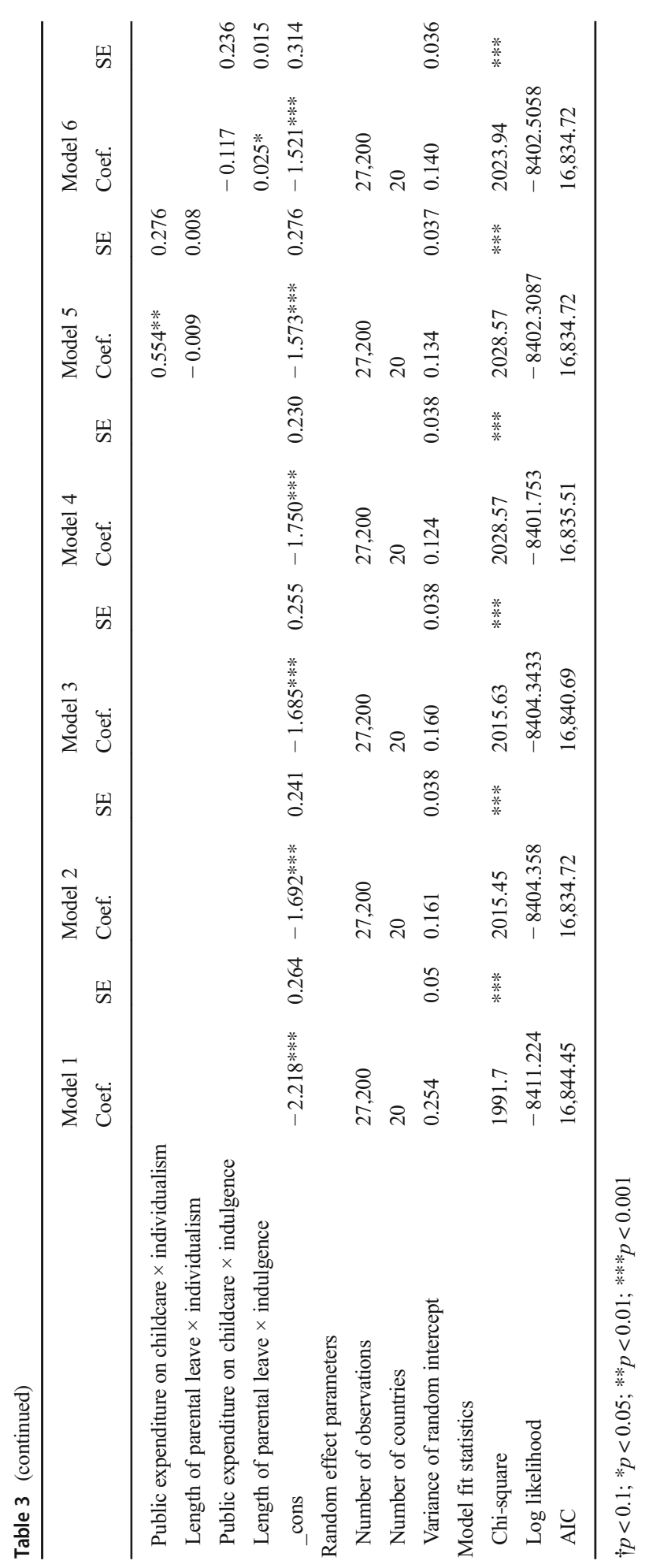




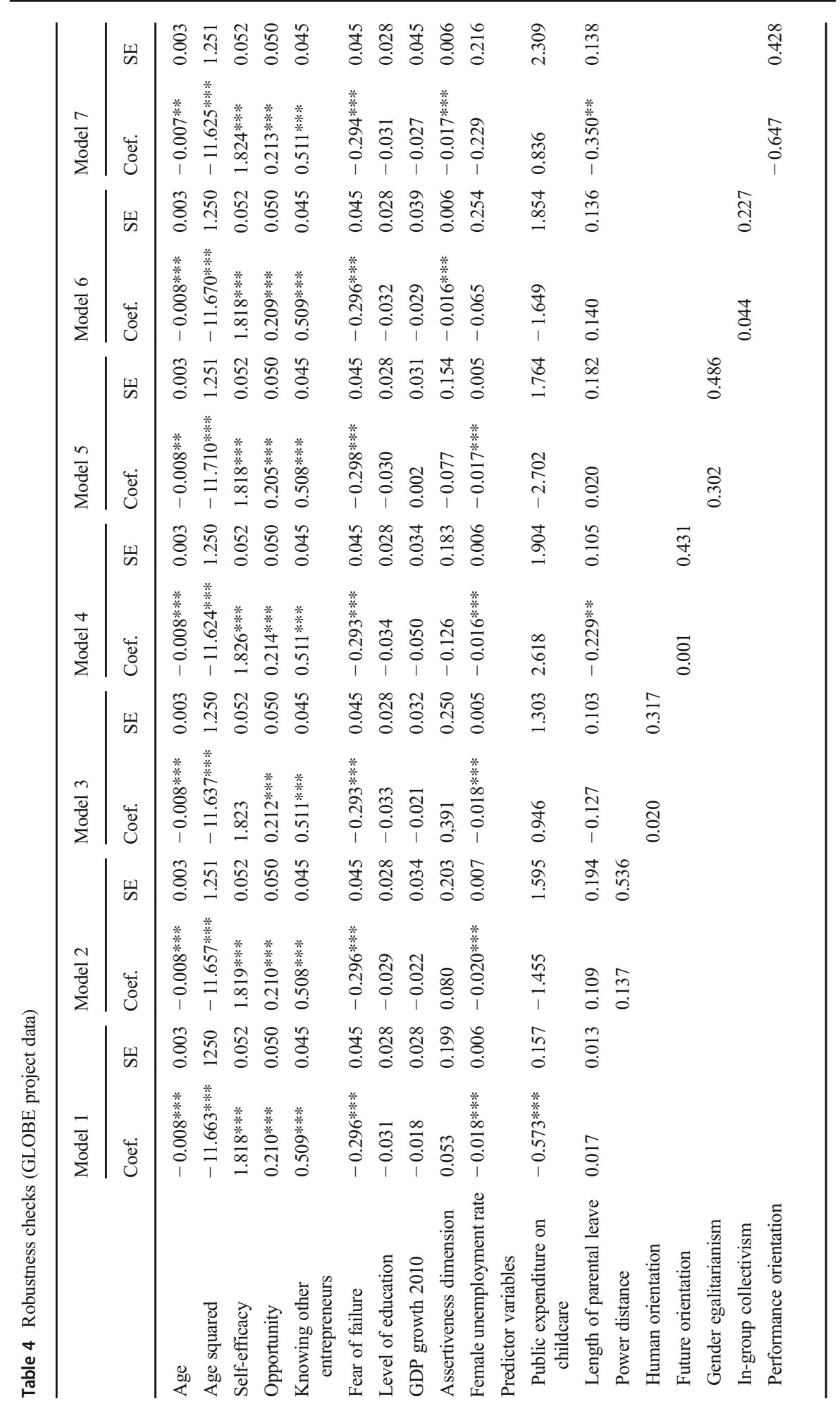




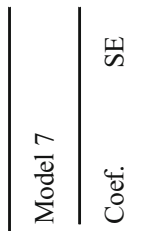

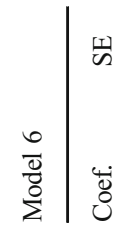

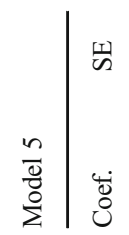

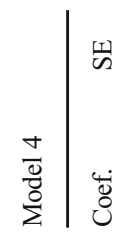

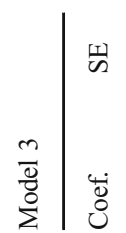

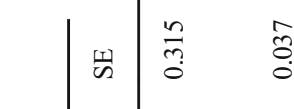

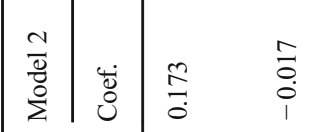

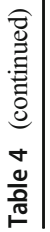

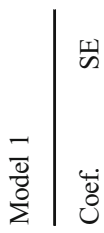

@.

$\sqrt{2}+2$

苛

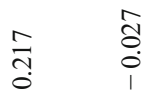

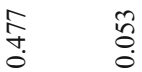

官

in

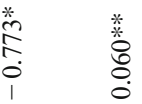

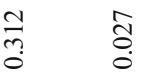

$\begin{array}{ll}\infty & \\ \infty & 0 \\ 0 & + \\ 1 & 0 \\ 1 & 0\end{array}$

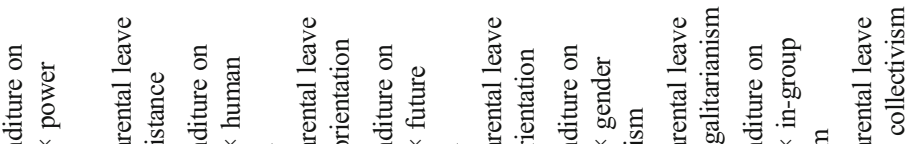

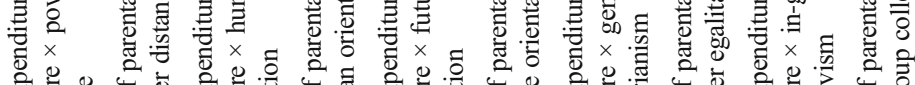

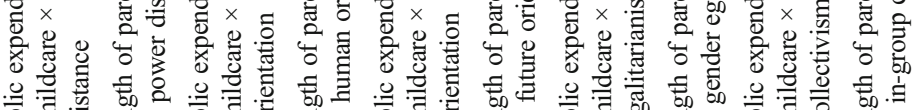

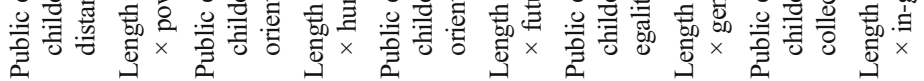




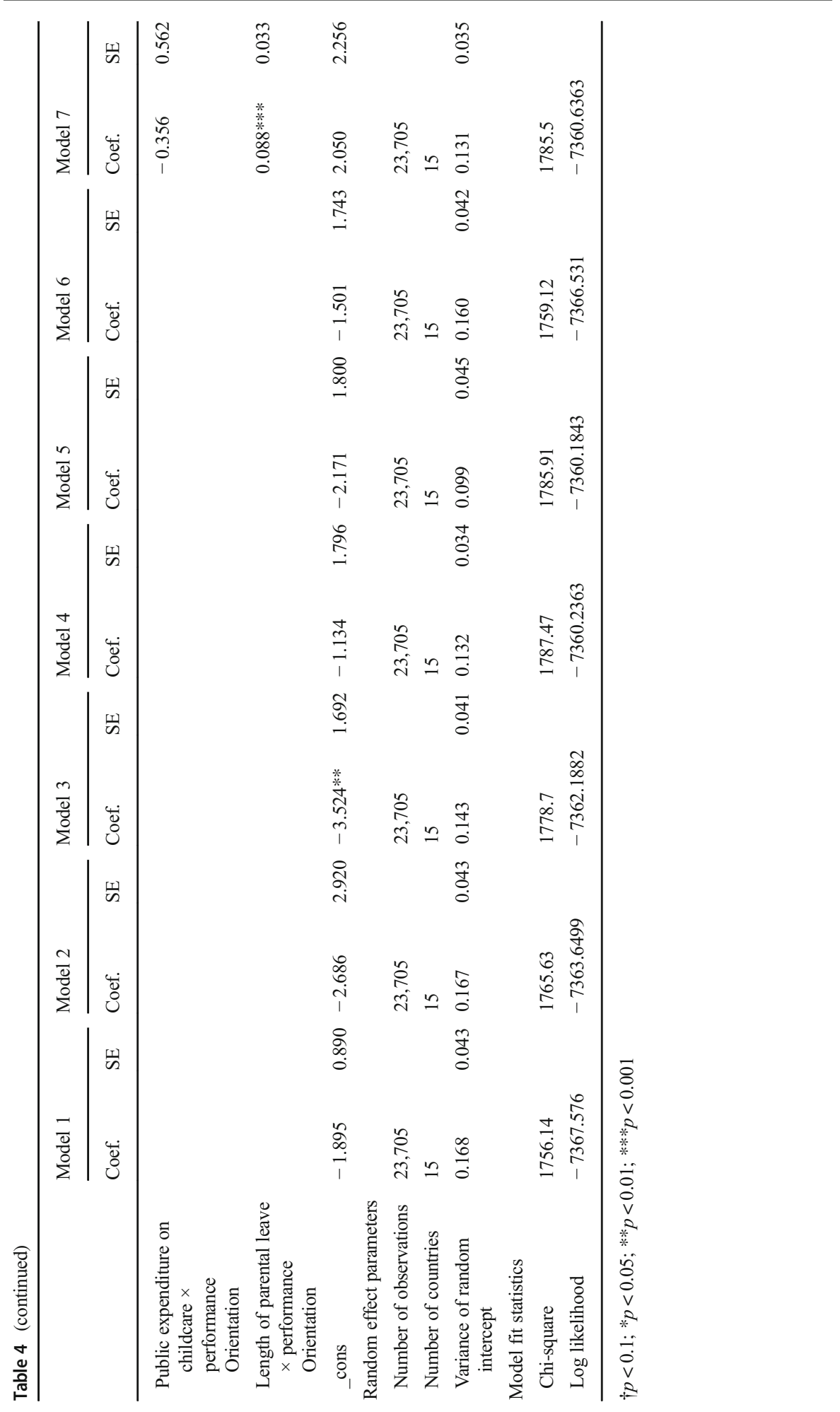


level were significant except the level of education. However, our control country-level variables were not significant. In model 2, we included our main effects. As expected, the relation between the public expenditure on childcare and the likelihood that women will become entrepreneur was negative and statistically significant $(\beta=-0.570$; $p<0.001)$. However, the relationship between the length of parental leave and the likelihood that women will become entrepreneurs was not significant ( $\beta=0.011$; ns). Thus, hypothesis 1 was partially supported. The variance component of the random intercept decreases from 0.254 in Model 1 to 0.161 in Model 2, suggesting that $36.699 \%(((0.254-0.161) / 0.254) \times 100)$ of the remaining variance (after accounting for the control variables) is explained by the three formal institutions. This result also means that the three formal institution predictors collectively explained $36.699 \%$ of the total country-level variance of the likelihood that a woman will become entrepreneur.

Models 3, 4, 5, 6, and 7 sequentially included the interaction terms. The interaction between family policies (the public expenditure on childcare and the length of parental leave) and power distance was not significant ( $\beta=-0.022$; ns, $\beta=0.001$; ns). Thus, hypotheses $2 \mathrm{a}$ and $2 \mathrm{~b}$ were not supported by our data. The interaction between public childcare and masculinity was negative and significant $(\beta=-0.158 ; p<0.05)$, providing support for hypothesis 3a. Nevertheless, the interaction between the length of parental leave and masculinity was not significant $(\beta=-0.009$; ns). This result represents that hypothesis $3 \mathrm{~b}$ was not supported. The interaction between individualism and the public expenditure on childcare was positive and statistically significant $(\beta=0.554$; $p<0.01)$, while that between individualism and the length of parental leave $(\beta=-$ 0.009 ; ns) was not significant. Therefore, hypothesis $4 \mathrm{a}$ was supported but hypothesis $4 \mathrm{~b}$ was not. Finally, model 6 shows that the interaction between indulgence and the public expenditure on childcare was not significant $(\beta=-0.117$; ns). Instead, the length of parental leave was positive and statistically significant $(\beta=0.025$; $p<0.05)$. The results did not support hypothesis 5a but did support hypothesis $5 \mathrm{~b}$. Model 6 shows that $0.129 \%(((0.161-0.124) / 0.161) \times 100)$ of the remaining variance is explained by the moderating effect of indulgence on formal institutions with respect to model 2 (this model includes control and independent variables).

\section{Robustness analysis}

To test the robustness of our results, we conducted additional analyses. We used a different measurement of the dependent variable: likelihood of men becoming entrepreneurs ("1"). In these analyses, the final sample consisted of 27,231 individuals from 20 countries. We analyzed the correlation matrix, and, again, we observe that uncertainty avoidance and the long-term dimensions were highly correlated to the independent variables. The findings indicate that the women and men's samples differ. The relationship between the public expenditure on childcare and the likelihood that women will become entrepreneurs was negative and significant, while the length of parental leave was positively and significantly associated with the likelihood of men becoming entrepreneurs. When we introduced the interaction terms, the findings suggest, on the one hand, that the interaction between power distance and the public expenditure on childcare was negative and statistically significant and, on the other hand, that the length of parental leave was positive and statistically significant. Moreover, the interaction between masculinity and the public expenditure on childcare was not significant. 
The interaction between masculinity and the length of parental leave was negative and significant. Then, the interaction term of individualism and the public expenditure on childcare was not significant, but the length of parental leave is negative and significant. Finally, the interaction between indulgence and the public expenditure on childcare did not have a statistically significant on the likelihood that men will become entrepreneurs. However, the interaction between indulgence and the length of parental leave was statistically significant and positive. Therefore, we observe that the main effect and the interaction terms influence women and men's likelihood of becoming entrepreneurs differently. Hence, formal and informal institutions have a differential effect on men and women entrepreneurs.

Moreover, using the Global Leadership \& Organizational Behavior Effectiveness (GLOBE) data, we reran our analyses. We first ran a correlation matrix and observed that institutional collectivism, uncertainty avoidance and the long-term dimensions had a high correlation with the public expenditure on childcare and the length of parental leave. Therefore, we did not include these dimensions in our analyses. Thus, we used human orientation, future orientation, gender egalitarianism, in-group collectivism, and performance orientation. The results have some similarities and differences to our results when we used the Hofstede dimensions. Similar to the results from the Hofstede dimensions, the GLOBE project results show that the interaction between the family policies and the power distance dimension did not have a significant effect on the likelihood that a woman will become entrepreneur. When we tested human orientation, we observed that the interaction between the family policies and the human orientation dimension does not influence women's likelihood of becoming entrepreneurs. However, the future orientation dimension shows different results: we observed that future orientation reduces significantly the effect of public childcare on the likelihood that women will become entrepreneurs. Moreover, future orientation amplifies the negative effect of the length of parental leave and women's likelihood of becoming entrepreneurs. Interestingly, gender egalitarianism and in-group collectivism did not have a significant effect on the relationship between the family policies and the likelihood that women will become entrepreneurs. Instead, performance orientation shows different results: the interaction between the public expenditure on childcare and performance orientation did not have a significant effect on women's likelihood of becoming entrepreneurs. However, the interaction between the length of parental leave and performance orientation was positive and statistically significant. These results show that the interaction between formal and informal institutions occurs when using different datasets. Additionally, the results give a robustness to our theoretical model and show how cultural dimensions increase or reduce the effect of the public expenditure on childcare and the length of parental leave on women's decision to start new ventures.

\section{Discussion and findings}

Building on arguments from institutional theory, as theorized by North (1990), we hypothesized that formal institutions, which differ across countries and are represented by family policies such as the public expenditure on childcare and the length of parental leave, have significant effects on the likelihood that women will become entrepreneurs. Furthermore, we hypothesized that informal institutions - such as power distance, 
masculinity, individualism, and indulgence - moderate the relationship between formal institutions and women's likelihood of starting ventures.

\section{The impact of formal institutions on the likelihood that women will become entrepreneurs}

The results from our study point to the important contribution of the public expenditure on childcare to the likelihood of women becoming entrepreneurs. In the context of new institutional theory in which formal institutions shape individual behaviors (North 1990), women's likelihood of becoming entrepreneurs is related to the role of formal institutions that cannot be easily changed and are difficult to control (Brush et al. 2009). Formal institutions such as family policies that aim at increasing the participation of women in the labor market also affect women's decisions to become entrepreneurs. Therefore, as our findings show, the public expenditure on childcare in a country strongly reduces a woman's desire to become entrepreneur.

However, in keeping with new institutional economics, institutions shape the likelihood of women becoming entrepreneurs. As institutions are created to reduce uncertainty (North 1990), the effect of formal institutions varies between women and men's decisions, in particular the decision to become entrepreneurs. Given the benefit for working parents to participate in the labor market, we expected a reduction of the likelihood that women will become entrepreneurs when parental leave is longer, as women prefer to be employed. However, our findings suggest that the length of parental leave does not have a significant effect on women entrepreneurs. This finding suggests the complexity of the institutional context surrounding women entrepreneurs (Brush et al. 2009).

Previous findings provide mixed results on the public expenditure on childcare and the length of parental leave (Estrin and Mickiewicz 2011; Thébaud 2015), suggesting the complex institutional context that women face when deciding to become entrepreneurs and the benefits that the labor market provides. Literature on women's entrepreneurship supports this perspective (Klyver et al. 2013), arguing that to increase the participation of women in entrepreneurship, public policies should be aligned and balanced with respect to entrepreneurship as well as the labor market (Ahl and Nelson 2010).

\section{The moderating role of informal institutions: cultural dimensions}

The findings suggest that high masculinity and individualism moderate the impact of the public expenditure on childcare on women's likelihood of becoming entrepreneurs. To better interpret these findings, we plot the significant interactions in Figs. 2, 3, and 4 $(p<0.05)$.

We observe that this effect occurs in countries characterized by medium and high levels of masculinity, such as the USA, Greece, France, and Japan. As shown in Fig. 2, the likelihood of a woman becoming an entrepreneur decreases when the public expenditure is high on childcare and with medium/high masculinity. These results are in line with the previous literatures, which show a negative relationship between the public expenditure on childcare and the likelihood of women becoming entrepreneurs (e.g., Estrin and Mickiewicz 2011; Thébaud 2015). By contrast, we observe that in 


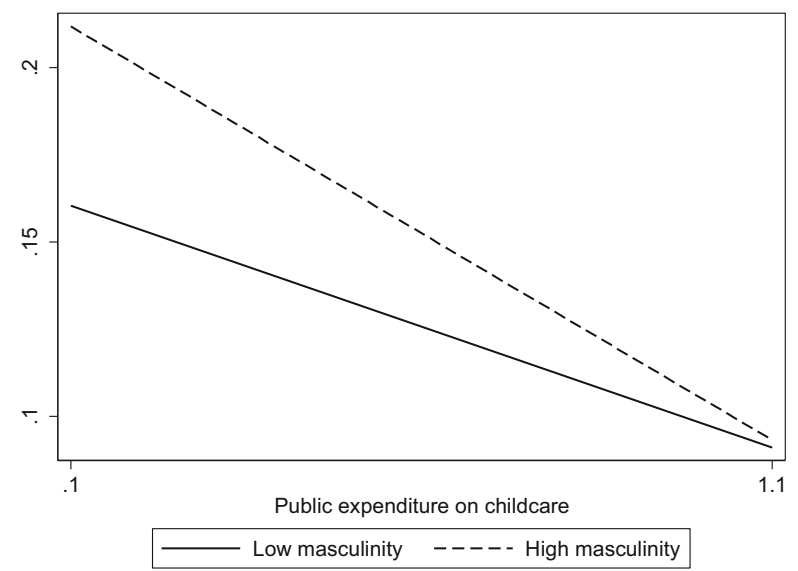

Fig. 2 Interaction between masculinity and the public expenditure on childcare on the likelihood of women becoming entrepreneurs

highly masculine countries, women entrepreneurs may perceive the benefits of the public expenditure on childcare, namely, public childcare facilities. These facilities help reduce the number of hours that women spend taking care of their children, but these benefits are mainly in the labor market. The public expenditure on childcare seems to strengthen traditional gender roles in the society because women would prefer to work in the labor market, leading to fewer women becoming entrepreneurs.

We plotted the significant interaction between individualism and public expenditure on childcare (see Fig. 3). The plot shows that, in low-individualistic countries, a higher public expenditure on childcare positively affects the likelihood of women becoming entrepreneurs. This effect only occurs in countries with low individualism (e.g., Greece, Korea, and Mexico). A possible explanation is that low-individualistic countries maintain traditional gender roles in society (Parboteeah et al. 2008); thus, family relations are more important than business ones. However, in high-individualistic societies, the public expenditure on childcare does not have a significant effect because gender equality may be embedded at the

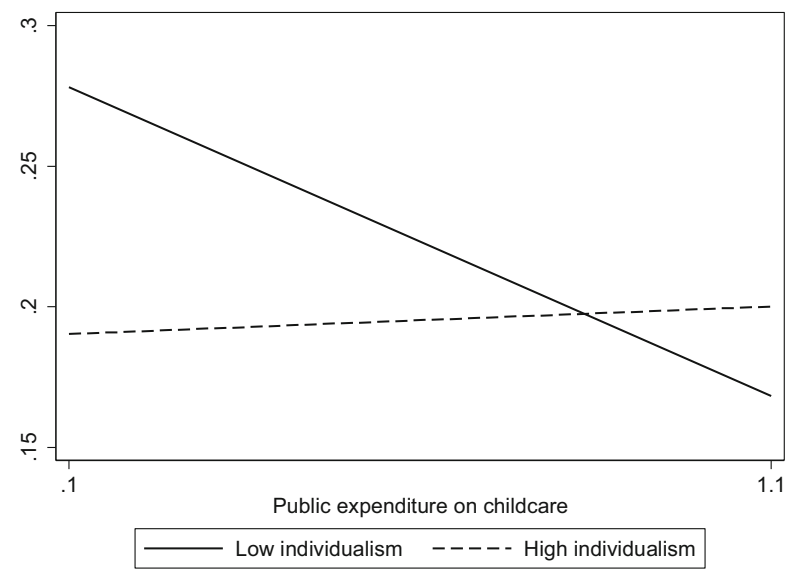

Fig. 3 Interaction between individualism and the public expenditure on childcare on the likelihood of women becoming entrepreneurs 


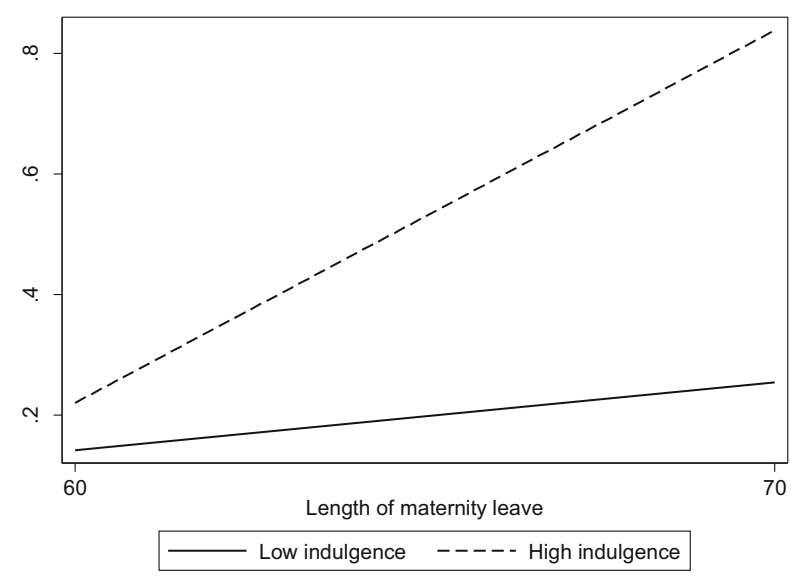

Fig. 4 Interaction between indulgence and the length of parental leave on the likelihood of women becoming entrepreneurs

society and women levels; therefore, women perceive that they have the same opportunities as men do (Fletcher 2006). Consequently, the impact of the public expenditure on childcare is not significant on women entrepreneurs in these types of societies.

Further, we plotted the significant interaction between indulgence and the length of parental leave (see Fig. 4). The plot shows that when indulgence increases, the length of parental leave increases the likelihood that women will become entrepreneurs. An explanation is that women are highly empowered in high-indulgent societies because having a long length of parental leave in a country may be perceived as a supportive state to employees as well as to entrepreneurs. Consequently, entrepreneurship seems a great opportunity for creating new ventures (Buttner and Moore 1997) because people are empowered and perceive they have the support of states. Entrepreneurship thus provides a way to decrease gender inequality (Bird and Brush 2002). Conversely, in a low-indulgent society, entrepreneurship may be perceived as an unconventional way to earn money (Baughn et al. 2006). For this reason, women would prefer to enter the labor market due to the security that labor markets provide. Therefore, the likelihood that a woman will become an entrepreneur decreases.

In our robustness checks, we ran our model on a sample of men to determine whether there were differences in becoming entrepreneurs and on GLOBE data to observe whether the interactions are significant using different cultural measures. Again, we found support that the interaction between formal and informal institutions influences men's likelihood to become entrepreneurs but in a different way than it does for women. For example, in the men-only sample, the interaction between power distance and family policies is significant, but in the women-only sample, it was not. Another example is that the interaction between masculinity and the length of parental leave is significant for the men-only sample, while in the women-only sample, this interaction is not significant, but the interaction between masculinity and the public expenditure on childcare is. These results highlight the role played by formal and informal institutions and give strong support to our arguments that institutions shape men and women entrepreneurial behaviors differently. This finding also suggests that the recent conversation in the entrepreneurship literature around the importance of the institutional context (Welter 2011) has a gendered component of cultural dimensions. 
Additionally, using GLOBE data provides a stronger support to our findings. Our robustness checks indicate that different cultural variables influence the relationship between formal institutions and women entrepreneurs, supporting the gendered component of culture. These results show that women are significantly sensitive to the institutional context (Welter 2011).

\section{Concluding remarks}

This study analyzed the way that informal institutions (masculinity, power distance, individualism and indulgence) moderate the relationship between formal institutions and the likelihood that women will become entrepreneurs. Based on institutional theory (North 1990), we observed that masculinity, individualism, and indulgence weaken the influence of the public expenditure on childcare on women's likelihood of starting new ventures. Our findings shed new light on the neglected role of informal institutions that facilitate or constrain women's entrepreneurship.

\section{Contributions to theory}

This study first contributes to the field of entrepreneurship (Autio et al. 2013; Thébaud 2015) because we could observe that the interactions of formal and informal institutions affect women's likelihood of becoming entrepreneurs. Through our robustness checks, we also observed that men's likelihood of becoming entrepreneurs is influenced by the interactions of formal and informal institutions; however, these effects differ between women and men samples. Our findings extend the literature of institutions and entrepreneurship in that we go deeper than testing the direct effect and find that their interactions play a key role in becoming entrepreneurs. Thus, we contribute to the literature that investigates entrepreneurship and institutions through a multi-level approach (De Clercq et al. 2013; Schölin et al. 2017; Stephan et al. 2015), in particular, by investigating the role that culture as an informal institution plays in entrepreneurship (Bruton et al. 2008; Engelen et al. 2009; Oo et al. 2018). Second, our findings extend the literature of women's entrepreneurship because we can observe the effect of the institutional context on their likelihood of becoming entrepreneurs. Even though the current literature has advanced on the reasons women are less likely than men to become entrepreneurs (e.g., Baughn et al. 2006; Estrin and Mickiewicz 2011), these studies have tested separately whether some formal or informal institutions influence them. Instead, in our study, we could observe the complex and important role that the interactions of public policies (formal institutions) and culture (informal institutions) have in women's likelihood of becoming entrepreneurs. We could see that family policies on their own have a significant effect but this effect is moderated to a great extent by informal institutions such as masculinity, individualism and indulgence. Third, we address the call for more comparative research in the women's entrepreneurship field by advancing both a macro-perspective (Autio et al. 2013; Yousafzai et al. 2015) and an examination of the variance in women's entrepreneurship across countries (Verheul et al. 2006). This study supports the notion that women's entrepreneurship has a multi-level nature (Elam and Terjesen 2010). Our findings suggest that women's behaviors such as becoming an entrepreneur are better explained when the institutional context is properly considered (Giménez and Calabrò 2018; Welter 2011). We thus advance the reasons why women's participation in entrepreneurship varies globally. 


\section{Implications for policy makers}

Based on our findings, we suggest to policymakers, who wish to increase the number of women entrepreneurs, to consider informal institutions when creating public policies. Since the effect of formal institutions, such as the public expenditure on childcare and the length of parental leave, varies across countries, particularly if the countries are characterized by high levels of masculinity, individualism and indulgence. Therefore, policy makers should analyze the cultural context and design public policy to be effective in a specific country. We also consider that public policies, which promote women's entrepreneurship, should be designed from a long-term perspective to reduce the effect of informal constraints in the future (e.g., masculinity, individualism, and indulgence) (Helmke and Levitsky 2004). Finally, we suggest that these policies should be continuously revised to assess their effectiveness.

\section{Limitations and future research directions}

Several limitations of this study should be noted. First, due to missing data, the sample size in our study was 20 countries. Future research should include developed, transitioning and developing economies, thus allowing for the observation of entrepreneurial dynamics in different countries and, possibly, different clusters. Second, although multi-level techniques are useful for considering different levels of analysis, we could use data only from 2010. Future research should increase the number of years used to examine patterns over time. Moreover, following Helmke and Levitsky (2004)'s typology of informal institutions, such as complementary and accommodating institutions, further studies could more deeply examine how the interaction between formal and informal institutions influences women's entrepreneurship. Third, by collecting data from mum-entrepreneurs, we could investigate the way that being a mom influences women either to become entrepreneurs or their growth aspirations. Fourth, although we compared women entrepreneurs and non-entrepreneurs, we suggest an examination of women's transitions from the labor market to entrepreneurship and of the formal and informal institutions that may influence this decision. Fifth, it would be interesting to study the nexus of institutions, women entrepreneurs and economic growth, considering female entrepreneurship as a mediator between the institutional context and economic performance (Aparicio et al. 2016). Finally, it would be interesting to examine further how institutional conditions affect women's motivation to become entrepreneurs to understand whether this motivation is driven by opportunity, necessity or purpose (pursuing social or sustainable ventures).

Acknowledgments We would like to thank the three anonymous referees and the editor, Prof. Hamid Etemad, for helping and guiding us to improve our study with their valuable comments. David Urbano acknowledges the financial support from the Spanish Ministry of Economy \& Competitiveness [project ECO2017-87885-P], the Economy \& Knowledge Department-Catalan Government [project 2017-SGR1056] and ICREA under the ICREA Academia Programme.

Funding Information Open Access funding provided by Projekt DEAL.

Open Access This article is licensed under a Creative Commons Attribution 4.0 International License, which permits use, sharing, adaptation, distribution and reproduction in any medium or format, as long as you give 
appropriate credit to the original author(s) and the source, provide a link to the Creative Commons licence, and indicate if changes were made. The images or other third party material in this article are included in the article's Creative Commons licence, unless indicated otherwise in a credit line to the material. If material is not included in the article's Creative Commons licence and your intended use is not permitted by statutory regulation or exceeds the permitted use, you will need to obtain permission directly from the copyright holder. To view a copy of this licence, visit http://creativecommons.org/licenses/by/4.0/.

\section{References}

Aguinis H, Gottfredson RK, Culpepper SA (2013) Best-practice recommendations for estimating cross-level interaction effects using multilevel modeling. J Manag 39:1490-1528

Ahl H, Nelson T (2010) Moving forward: institutional perspectives on gender and entrepreneurship. Int J Gend Entrep 2:5-9

Alvarez C, Urbano D (2011) Environmental factors and entrepreneurial activity in Latin America. Acad Rev Latinoamer Adm 48:126-139

Aoki M (2001) Toward a comparative institutional analysis. MIT press, Cambridge, MA

Aparicio S, Urbano D, Audretsch D (2016) Institutional factors, opportunity entrepreneurship and economic growth: panel data evidence. Technol Forecast Soc Chang 102:45-61

Autio E, Pathak S, Wennberg K (2013) Consequences of cultural practices for entrepreneurial behaviors. J Int Bus Stud 44:334-362

Baskerville RF (2003) Hofstede never studied culture. Acc Organ Soc 28:1-14

Baughn CC, Chua BL, Neupert KE (2006) The normative context for women's participation in entrepreneurship: a multicountry study. Enterp Theory Pract 30:687-708

Bergemann A, Riphahn RT (2010) Female labour supply and parental leave benefits-the causal effect of paying higher transfers for a shorter period of time. Appl Econ Lett 18:17-20

Bertrand M, Goldin C, Katz LF (2010) Dynamics of the gender gap for young professionals in the financial and corporate sectors. Am Econ J Appl Econ 2:228-255

Bird B, Brush C (2002) A gendered perspective on organizational creation. Enterp Theory Pract 26:41-66

Brush CG, de Bruin A, Welter F (2009) A gender-aware framework for women's entrepreneurship. Int J Gend Entrep 1:8-24

Bruton G, Ahlstrom D, Obloj K (2008) Entrepreneurship in emerging economies: where are we today and where should the research go in the future entrepreneurship. Enterp Theory Pract 32:1-14

Bruton G, Ahlstrom D, Li HL (2010) Institutional theory and entrepreneurship: where are we now and where do we need to move in the future? Enterp Theory Pract 34:421-440

Burch T (2013) Why the world needs women entrepreneurs. De Economist https://www.economist. com/news/2013/11/18/why-the-world-needs-women-entrepreneurs Accessed 30 Sept 2017

Buttner EH, Moore DP (1997) Women's organizational exodus to entrepreneurship: self-reported motivations and correlates with success. J Small Bus Manag 35:34-46

De Clercq D, Lim DS, Oh CH (2013) Individual-level resources and new business activity: the contingent role of institutional context. Enterp Theory Pract 37:303-330

Elam A, Terjesen S (2010) Gendered institutions and cross-national patterns of business creation for men and women. Eur J Dev Res 22:331-348

Engelen A, Heinemann F, Brettel M (2009) Cross-cultural entrepreneurship research: current status and framework for future studies. J Int Entrep 7:163-189

Estrin S, Mickiewicz T (2011) Institutions and female entrepreneurship. Small Bus Econ 37:397-415

Fletcher DE (2006) Entrepreneurial processes and the social construction of opportunity. Entrep Reg Dev 18: $421-440$

Fuwa M (2004) Macro-level gender inequality and the division of household labor in 22 countries. Am Sociol Rev 69:751-767

Fuwa M, Cohen PN (2007) Housework and social policy. Soc Sci Res 36:512-530

Geist C (2005) The welfare state and the home: regime differences in the domestic division of labour. Eur Sociol Rev 21:23-41

Giménez D, Calabrò A (2018) The salient role of institutions in women's entrepreneurship: a critical review and agenda for future research. Int Entrep Manag J 14:857-882

Goltz S, Buche MW, Pathak S (2015) Political empowerment, rule of law, and women's entry into entrepreneurship. J Small Bus Manag 53:605-626. https://doi.org/10.1111/jsbm.12177 
Gornick JC, Meyers MK (2003) Families that work: policies for reconciling parenthood and employment. Russell Sage Foundation, New York

Gornick JC, Meyers M (2009) Institutions that support gender equality in parenthood and employment. In: Wright EO, Gornick JC, Meyers M (eds) Gender equality: transforming family divisions of labor, vol 6. Verso Books, London

Hair JF, Anderson RE, Tatham RL, Black WC (1998) Multivariate data analysis. Prentice Hall, Englewood Cliffs

Hegewisch A, Gornick JC (2011) The impact of work-family policies on women's employment: a review of research from OECD countries. Community Work Fam 14:119-138

Helmke G, Levitsky S (2004) Informal institutions and comparative politics: a research agenda. Perspect Polit 2:725-740

Henry C, Marlow S (2014) Exploring the intersection of gender, feminism and entrepreneurship. In: Fayolle A (ed) Handbook of research in entrepreneurship. Edward Elgar Publishing, Cheltenham, pp 109-126

Hofmann DA (1997) An overview of the logic and rationale of hierarchical linear models. J Manag 23:723-744

Hofstede G (1980) Culture and organizations. Int Stud Manag Organ:15-41

Hofstede G (1983) The cultural relativity of organizational practices and theories. J Int Bus Stud:75-89

Hofstede G (2001) Culture's consequences: comparing values, behaviors, institutions and organizations across nations. Sage Publications Inc, Thousand Oaks

Hofstede G (2011) Dimensionalizing cultures: the Hofstede model in context. Online Readings. Psychol Cult 2:8

Hofstede G, Hofstede GJ, Minkov M (2010) Cultures and organizations: software of the mind vol 3. McGrawHill, London

Hox JJ, Moerbeek M, van de Schoot R (2010) Multilevel analysis: techniques and applications. Routledge, New York

Jepperson R (1991) Institutions, institutional effects, and institutionalism. In: Powell W, DiMaggio PJ (eds) The new institutionalism in organizational analysis. University of Chicago Press, Chicago, pp 143-163

Kelley D et al (2017) Global entrepreneurship monitor 2016/2017 report on Women's entrepreneurship. Babson Collegue, Smith Collegue and the Global Entrepreneurship Research Association http://www. gemconsortium.org/report Accessed 20 Sept 2017

Klyver K, Nielsen SL, Evald MR (2013) Women's self-employment: an act of institutional (dis)integration? A multilevel, cross-country study. J Bus Ventur 28:474-488

Kobeissi N (2010) Gender factors and female entrepreneurship: international evidence and policy implications. J Int Entrep 8:1-35

Langowitz N, Minniti M (2007) The entrepreneurial propensity of women entrepreneurship. Theory Pract 31: $341-364$

Lee JH, Sohn SY, Ju YH (2011) How effective is government support for Korean women entrepreneurs in small and medium enterprises? J Small Bus Manag 49:599-616

Levesque M, Minniti M (2006) The effect of aging on entrepreneurial behavior. J Bus Ventur 21:177-194

Li Y, Zahra SA (2012) Formal institutions, culture, and venture capital activity: a cross-country analysis. J Bus Ventur 27:95-111

Mandel H, Semyonov M (2005) Family policies, wage structures, and gender gaps: sources of earnings inequality in 20 countries. Am Sociol Rev 70:949-967

Mandel H, Semyonov M (2006) A welfare state paradox: state interventions and Women's employment opportunities in 22 countries. Am J Sociol 111:1910-1949

Mattis MC (2004) Women entrepreneurs: out from under the glass ceiling. Women Manag Rev 19:154-163

McGowan P, Redeker CL, Cooper SY, Greenan K (2012) Female entrepreneurship and the management of business and domestic roles: motivations, expectations and realities. Entrep Reg Dev 24:53-72

McGrath RG, MacMillan IC, Scheinberg S (1992) Elitists, risk-takers, and rugged individualists? An exploratory analysis of cultural differences between entrepreneurs and non-entrepreneurs. J Bus Ventur 7:115-135

Misra J, Moller S, Budig MJ (2007) Work-family policies and poverty for partnered and single women in Europe and North America. Gend Soc 21:804-827

Mitchell RK, Smith B, Seawright KW, Morse EA (2000) Cross-cultural cognitions and the venture creation decision. Acad Manag J 43:974-993

Noguera M, Alvarez C, Urbano D (2013) Socio-cultural factors and female entrepreneurship. Int Entrep Manag J 9:1-15

Nooteboom B (2002) Trust: forms, foundations, functions, failures and figures. Edward Elgar Publishing

North DC (1990) Institutions, institutional change and economic performance. Cambridge university press, Cambridge

OECD (2015) OECD family database. OECD, Paris

Oo PP, Sahaym A, Juasrikul S, Lee S-Y (2018) The interplay of entrepreneurship education and national cultures in entrepreneurial activity: a social cognitive perspective. J Int Entrep:1-23 
Parboteeah KP, Hoegl M, Cullen JB (2008) Managers' gender role attitudes: a country institutional profile approach. J Int Bus Stud 39:795-813

Pettit B, Hook JL (2009) Gendered tradeoffs: women, family, and workplace inequality in twenty-one countries. Russell Sage Foundation, New York

Powell GN, Eddleston KA (2013) Linking family-to-business enrichment and support to entrepreneurial success: do female and male entrepreneurs experience different outcomes? J Bus Ventur 28:261-280

Reynolds P et al (2005) Global entrepreneurship monitor: data collection design and implementation 19982003. Small Bus Econ 24:205-231

Schölin T, Ohlsson H, Broomé P (2017) The role of regions for different forms of business organizations. Entrep Reg Dev 29:197-214

Simón-Moya V, Revuelto-Taboada L, Guerrero RF (2014) Institutional and economic drivers of entrepreneurship: an international perspective. J Bus Res 67:715-721

Stephan U, Uhlaner LM, Stride C (2015) Institutions and social entrepreneurship: the role of institutional voids, institutional support, and institutional configurations. J Int Bus Stud 46:308-331

Terjesen S, Hessels J, Li D (2013) Comparative international entrepreneurship: a review and research agenda. J Manag 42:299-344

Thébaud S (2015) Business as plan B: institutional foundations of gender inequality in entrepreneurship across 24 industrialized countries. Adm Sci Q 60:671-711

Thébaud S (2016) Passing up the job: the role of gendered organizations and families in the entrepreneurial career process. Enterp Theory Pract 40:269-287

Tonoyan V, Strohmeyer R, Habib M, Perlitz M (2010) Corruption and entrepreneurship: how formal and informal institutions shape small firm behavior in transition and mature market economies. Enterp Theory Pract 34:803-831

Trompenaars F, Hampden-Turner C (1998) Riding the waves of culture. McGraw-Hill, New York

Verheul I, Stel AV, Thurik R (2006) Explaining female and male entrepreneurship at the country level. Entrep Reg Dev 18:151-183

Welter F (2011) Contextualizing entrepreneurship — conceptual challenges and ways forward. Enterp Theory Pract 35:165-184

Welter F, Smallbone D (2011) Institutional perspectives on entrepreneurial behavior in challenging environments. J Small Bus Manag 49:107-125

Williamson OE (2000) The new institutional economics: taking stock, looking ahead. J Econ Lit 38:595-613

Yousafzai SY, Saeed S, Muffatto M (2015) Institutional theory and contextual embeddedness of women's entrepreneurial ;eadership: evidence from 92 countries. J Small Bus Manag 53:587-604

Publisher's note Springer Nature remains neutral with regard to jurisdictional claims in published maps and institutional affiliations.

\section{Affiliations}

\section{Daniela Gimenez-Jimenez ${ }^{1} \cdot$ Andrea Calabrò $^{2}$ • David Urbano ${ }^{3}$}

Daniela Gimenez-Jimenez

daniela.gimenez@tum.de

Andrea Calabrò

a.calabro@ipag.fr

David Urbano

david.urbano@uab.cat

1 TUM School of Management, Technische Universität München, Alte Akademie, 85354 Freising, Germany

2 IPAG Family Business Institute (IFBI), IPAG Business School, 4 bd Carabacel, 06000 Nice, France

3 Department of Business and Centre for Entrepreneurship and Social Innovation Research (CREIS), Universitat Autonoma de Barcelona, Edifici B, Campus UAB, 08193 Bellaterra, Barcelona, Spain 